\title{
National Health Insurance: The first 18 months
}

The principles for developing National Health Insurance (NHI) as described in the Green Paper are to improve access to quality healthcare services for the whole population and to provide financial risk protection against health-related catastrophic expenditures ${ }^{[1]}$ (Table 1). Comprehensive healthcare will be provided through accredited and contracted public and private providers, with a strong focus on health promotion and prevention services at the community and household level. The first 5 years will focus on strengthening the public sector in preparation for new NHI systems, with the launch of the new central NHI fund envisaged in 2014/15. We review progress since the Green Paper was launched in August 2011 , and summarise a more in-depth review just completed. ${ }^{[2]}$

\section{Progress - NHI policy}

The National Department of Health (NDOH) has consulted with medical scheme administrators, labour, the pharmaceutical industry, professional associations for various occupations, statutory bodies, government departments, academia, civil society and Parliament. Since the launch of the NHI Green Paper, over 100 submissions have been made to the $\mathrm{NDOH}$, and an international conference was held to exchange experience of introducing universal coverage in other countries. ${ }^{[3]}$ In visiting each of the 11 NHI pilot districts, the Minister of Health has met over 15300 stakeholders. The first cohort of 11 pilot districts was launched in April 2011 and covers every province, focusing on under-served communities ${ }^{[4]}$ (Tables 2 and 3). Dedicated funds catalyse experimentation and the setting up of new systems and capacities. Special links with academic groups specialising in health systems and public health research provide an opportunity for 'bottom-up' learning to inform central policy and the roll out in other districts. The Government's White Paper, expected in 2013, will be followed by further consultations and development of a final NHI policy, after which the legislative process will ensue.

\section{Progress - preparing for new arrangements under $\mathrm{NHI}$}

In the future, health services will be purchased from accredited public and private providers of services. In the short term, the scope and quality of public services must be improved, with private services contracted where they add value. International experience on defining packages of services has been studied and a starting point for South Africa (SA) is ensuring that a list of 'non-negotiable' services are adequately budgeted for and provided in all districts. ${ }^{[5]}$ Global experience shows the importance of primary healthcare (PHC) being at the centre of service delivery, promoting good health, preventing illness, and acting as the first point of contact for most healthcare. The PHC platform in SA is being established across the country based on three complementary components:

- Ward-based PHC agents. Approximately $25 \%$ of the 40000 community health workers have been re-trained in the new, national approach to community-orientated PHC.

- School health services. The national policy ${ }^{[6]}$ focuses on the most disadvantaged schools, with mobile clinics to support preventive and health promotion services aimed at reducing health barriers to learning, and facilitating access to other services.

- District clinical specialist teams. These teams will focus on improving the health of mothers, newborns and children. ${ }^{[7}$
Every district will have a senior obstetrician and gynaecologist, paediatrician, family physician, midwife, paediatric nurse and PHC nurse. Over $43 \%$ of positions have been filled, and the induction programme for these professionals is underway.

An audit of the quality of all public sector facilities has been completed and improvement teams are working in the NHI pilot districts to help ensure that the many problems identified are being systematically addressed. Work is underway with provinces to plan, manage, modernise, rationalise and transform infrastructure This includes expanding on existing facilities, building new infrastructure where long-term solutions are required, and using mobile or prefabricated facilities to resolve acute problems. Major infrastructure projects are also underway in five tertiary hospitals: Limpopo Academic, Chris Hani Baragwanath Academic, Dr George Mukhari, Nelson Mandela Academic and King Edward VIII.

\section{Table 1. Objectives of NHI}

1. To improve access to quality health services for all South Africans, irrespective of whether they are employed or not

2. To pool risks and funds so that equity and social solidarity will be achieved through the creation of a single fund

3. To procure services on behalf of the entire population and efficiently mobilise and control key financial resources

4. To strengthen the under-resourced and strained public sector so as to improve health systems performance

\begin{tabular}{ll} 
Table 2. NHI pilot districts & \\
\hline District (population, 2012) & Province \\
\hline OR Tambo (1 754 499) & Eastern Cape \\
Thabo Mofutsanyane (771 610) & Free State \\
City of Tshwane (2 520 435) & Gauteng \\
Amajuba (517 279) & KwaZulu-Natal \\
uMgungundlovu (1 071 606) & KwaZulu-Natal \\
Umzinyathi (517 806) & KwaZulu-Natal \\
Vhembe (1 312.197) & Limpopo \\
Gert Sibande (946 719) & Mpumalanga \\
Pixley ka Seme (192 572) & Northern Cape \\
Dr Kenneth Kaunda (905 675) & North West \\
Eden (567 993) & Western Cape
\end{tabular}

\section{Table 3. Objectives of pilots}

1. To assess the ability of districts to assume greater responsibility with a 'purchaser-provider split'

2. To assess the feasibility, acceptability, effectiveness and affordability of engaging the private sector

3. To assess the costs of introducing a fully fledged district health authority and the implications for scaling up 
Human resources are a key constraint, ${ }^{[8]}$ and staff norms are being finalised with World Health Organization support. ${ }^{[9]}$ The production of new doctors and nurses has been increased with an additional 165 medical student places in South Africa, and 95 medical specialists will be recruited from Cuba. The recommendations of the 2011 Nursing Summit have been taken forward with the launch of the national Strategic Plan for Nursing Education, Training and Practice in February 2013. Following a national assessment of competencies and a review of job descriptions for hospital CEOs, almost all of 118 new CEO positions have been filled, and their induction got under way in early 2013. In future, all senior managers will be required to undergo specialist training and be accredited by a new South African Leadership and Management Academy. ${ }^{[10,11]}$

Technology will play a major role in improving outcomes and the delivery of services, but can be costly. A rigorous, independent mechanism to assess the cost-effectiveness of new technology is required, building on experience of other countries. ${ }^{[12]}$ The recently launched national e-health strategy also aims to harness information communication technologies to help transform the health system. ${ }^{[13]}$

The transformation of the health system requires closer engagement of local communities. Strengthening clinic committees and hospital boards remains a priority, and new guidance on this is being prepared.

Under the future NHI, there will be a clearer delineation of functions between those responsible for purchasing services, and those, both public and private, responsible for providing them. It will be several years before this 'purchaser-provider split' will be fully operational, but opportunities are already arising for exploring these new relationships. For example, in early 2013 the NDOH will contract approximately 600 private general practitioners in the 11 pilot NHI districts to provide services for communities that are currently under-served. Local agreements will help ensure that these new services are integrated into the current PHC model, including:

- health promotion and preventive care focusing on noncommunicable diseases, mother and child health, HIV and tuberculosis

- referrals from PHC nurses, ward-based PHC agents and school health teams

- chronic disease management using specially designed patient records

- antenatal and postnatal care services as determined by the clinical protocols

- clinical governance and capacity building of the PHC team.

Work has also started with central hospitals in Gauteng to prepare them for future financing under NHI. This focuses on improved resource management, administration, information systems, and governance through strengthening boards.

Countries with universal coverage have well-established mechanisms for pooling funding to address equity, efficiency and sustainability of health expenditures; the $\mathrm{NDOH}$ is therefore examining the options for introducing a set of tariffs backed up with appropriate legislation. Legislation has already been passed to enable the Office for Health Standards and Compliance to accredit public and private facilities, based on established national standards. It has already started voluntary inspections, which will soon be mandatory. The Bill has been approved for the establishment of the South African Health Products Regulatory Body to register and control the medicines and medical devices to be available in SA and due to be launched as an independent body in 2013. An institutional mechanism is also required to guide the uptake of new health technology under NHI, backed up by appropriate legislation.
NHI will require effective delegations of responsibilities linked to improved oversight and accountability at all levels. The $\mathrm{NDOH}$ is exploring the options for and costs of establishing District Health Authorities (DHAs). This will require considerable efforts to strengthen the capacity of district management teams in areas such as financial management, planning, monitoring, evaluation and contracting. The $\mathrm{NDOH}$ is also preparing guidance for strengthening hospital boards in the public sector and will be seeking stronger oversight and accountability of central hospitals.

The future NHI will be reliant on an effective information system. Considerable efforts are required to improve the quality, coverage and standardisation of information across the public and private systems. National indicators and targets have now been agreed for priority areas in the Negotiated Service Delivery Agreement for Health through the work of the Health Data Advisory and Coordination Committee. ${ }^{[14]}$ Health facility data on public and private providers have been loaded onto a new National Health Information Repository and Database, together with information on service access and determinants of health, that will be made available to provinces, districts and service providers. A new system of population registration is being developed in partnership with the Department of Science and Technology and the Council for Scientific and Industrial Research (CSIR). NHI will require a 'National Health Data Dictionary' using various coding systems. In this regard, the ICD-10 (10th revision of the International Statistical Classification of Diseases) system is not yet operating satisfactorily and will need to be strengthened. Coding systems permitting case-based hospital payment (e.g. diagnostic related groups), unique provider numbers, facility numbers, specialty codes, and laboratory results encoding are to be developed. Patient records in both primary and hospital-based care need considerably more work, building on the innovations already in use across the country. As one of its primary objectives, the national e-health strategy seeks to better co-ordinate and bring synergy to these efforts.

New national institutions are also required for NHI to function, each with bodies to oversee their work. The Office for Health Standards and Compliance, to be launched in 2013, will report directly to the Minister. The Green Paper provided estimates of the additional revenue required to implement the NHI over 14 years, and the Treasury has now updated the model used for this assessment. In addition the $\mathrm{NDOH}$ has commissioned a detailed assessment of costs to inform planning. This will focus on the specific intervention requirements for each pilot district. These will include strengthening district (and sub-district) management teams and creating district health authorities, developing a comprehensive service benefits scheme, strengthening health facilities, strengthening the three PHC streams, contracting private providers, strengthening emergency medical services, strengthening referral systems, and attending to other preparatory activities related to specific district needs. The Treasury is working on options for raising revenue for the future NHI, which include consideration of a payroll tax (payable by both employees and employers), a higher value-added tax rate or a surcharge on taxable income, or some combination of these. The $\mathrm{NDOH}$ has provided R150 million to develop new systems and capacities in pilot districts and central hospitals, provided through a new conditional grant, and these 'NHI business plans' will be scaled up in 2013/14, to R350 million.

\section{Challenges, risks and their mitigation}

As the quality of public sector services improves, there is likely to be an increase in their use, which will have implications for the rest of 


\section{EDITORIALS}

the sector and will require further analysis and consultation. Similarly, greater consultation is required to better understand the implications of increased demand for services from medical specialists, general practitioners, and other health professions. The forthcoming NHI White Paper will provide further opportunities for the $\mathrm{NDOH}$ to consult and discuss the vision of NHI and its implications with a wide range of stakeholders.

Making change happen will be difficult at first, and senior Facility Improvement Project Managers in each province, reporting directly to Heads of Departments and the $\mathrm{NDOH}$, will oversee the implementation of NHI business plans in each district. Learning from experience is critically important, and formal evaluations and operational research will therefore be required. Keeping the equity focus of NHI will entail special effort in under-served populations such as in informal settlements and deep rural areas.

\section{The way forward}

SA is building a better understanding of what NHI is and why it must be implemented. The NDOH has agreed on a timetable for implementation of NHI, which, while ambitious by international standards, is possible. Even so, it will take time for these major changes to impact on people's lives, and expectations will need to be carefully managed. Universal coverage is no longer a dream for SA and will become increasingly certain if all players work and strive together.

\section{P Matsoso}

Director-General, National Department of Health

\section{R Fryatt}

Senior Adviser, seconded to the National Department of Health from the UK Department for International Development

fryatb@health.gov.za

1. National Health Insurance in South Africa. Policy (Green) Paper. Pretoria: Department of Health, 201 . South African Health Review 2012. Health Systems Trust, February 2013.

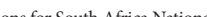
Con Cons

Ther 2012/13-2013/14. Sub-programme: Nation grova/docs/stratdocs/2012/app2012.pdf (accessed 5 February 2013). 5. Minister of Health. NHI pilots presentation. http://www.doh.gov.za/docs/presentations/2012/nhipilot. pdf (accessed 5 February 2013).

6. National Departments of Health and Basic Education. Integrated School Health Policy, October 2012.

7. Diste Clingaspent District Clinical Specialist Teams in South Africa. Ministerial lask Team Report. July 2012. http://www doh.gov.za/docs/reports/2012/District_Clinical_Specialist_Teams_in_South_Africa_Report.pdf (accessed
February 2013).

8. Human Resources for Health Strategy. 2012/13 - 2016/17. Pretoria: National Department of Health, 2011 9. Workload Indicators of Staffing Need (WISN) User Manual. World Health Organization. 1999. http: Www.who.int/hrh/resources/wisn_user_manual/en/ (accessed 5 February 2013).

0. Launch of the Academy for Leadership and Managentin doh.gov.za/show.php?id=3806 (accessed 5 February 2013)

1. Dudley L, Selebano IE, Nathan R, et al. Re-launch of the South African Society of Medical Managers (previously known as the Medical Administrators Group). S Afr Med J 2013;103(1):23.

2. UK National Institute for Health and Clinical Excellence. http://www.nice.org.uk (accessed 5 February 2013). 13. E-health strategy, South Africa. 2012-16. Pretoria: National Department of Health, 2012 .

14. National Department of Health. Health Data Advisory and Co-ordination Committee Report 2012 Pretoria: National Department of Health, 2012.

S Afr Med J 2013;103(3):156-158. DOI:10.7196/SAMJ.6601 